\title{
Prémio Ferreira da Silva 1984
}

O prémio Ferreira da Silva foi instituído pela SPQ e, de acordo com o seu regulamento, «é atribuído bienalmente ao Químico português que pelo trabalho produzido em Portugal no período de dois anos imediatamente anteriores ao da atribuição do prémio, mais tenha contribuido para o avanço da Quimica em qualquer das suas áreas». Este prémio, cujo objectivo é o de encorajar a qualidade e quantidade de investigação científica em Portugal, foi atribuído pela primeira vez em 1982 ao Prof. Jorge Calado (IST) e foi partilhado em 1984 pelos professores Sebastião J. Formosinho (Univ. de Coimbra) e António A.V. Xavier (Univ. Nova de Lisboa).

As notas que se seguem referem aspectos do trajecto cientifico dos últimos laureados. O Boletim da SPQ agradece aos Professores Sílvia M.B. Costa (IST) e José J. Moura (UNL) a sua colaboração pela elaboração destas notas.

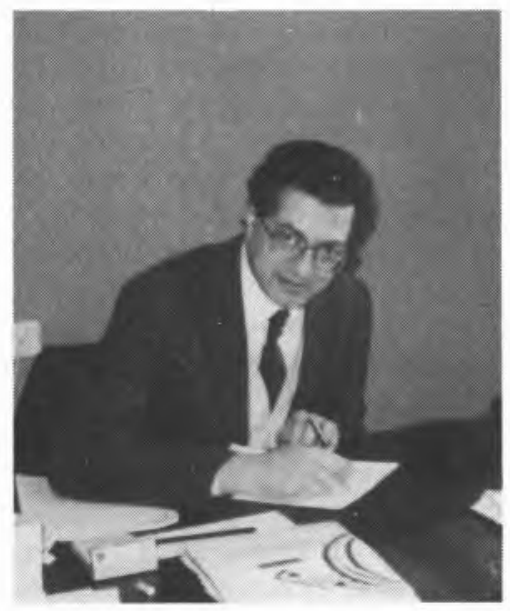

A Sociedade Portuguesa de Química distinguiu em 1984, ex-aequo, Sebastião J. Formosinho pela contribuição para o desenvolvimento da Investigação em Química em Portugal. Parece pois apropriado escrever algumas notas sobre a sua carreira científica, que tem contribuído para prestigiar a Universidade Portuguesa.

Sebastião Formosinho completou os estudos universitários em Coimbra, em 1964, com a licenciatura em Ciências Físico-Químicas, revelando desde logo uma grande aptidão para matérias de índole teórica no domínio da Química-Física Molecular. Assim, iniciou trabalhos de investigação no domínio da Espectroscopia Molecular publicando nesta fase (1965-1968) dois artigos sobre Cálculos de Orbitais Moleculares.

Em 1968 iniciou a sua tese de Doutoramento em Fotoquímica sob a orientação do Professor Sir George Porter, F.R.S. (prémio Nobel da Química em 1967) sendo sempre considerado quer pelo Supervisor quer pelos colegas um doutorando brilhante, com uma invulgar capacidade intelectual e preparação científica. Aliás, a atestá-lo, o facto de que, ainda antes de concluir o doutoramento, substituiu o Professor
Porter, a pedido deste, numa conferência convidada integrada num Simpósio que reuniu em 1971 grandes especialistas no domínio das Transições não Radiativas. Da sua Tese e ainda de outros trabalhos de investigação feitos em colaboração com a equipa da Royal Institution da Grã-Bretanha no período de 1968-1971, resultaram nove publicações versando o tema dos Processos Fotofísicos de Moléculas Aromáticas no Estado Gasoso.

Sem pretender aqui fazer uma análise muito exaustiva do seu Curriculum Vitae, gostaria, no entanto, de salientar a proposta de um modelo do Efeito de Túnel para Transições não Radiativas sobre o qual começou a trabalhar logo após o seu regresso a Portugal.

Dada a novidade dos conceitos apresentados, que colidiram em parte com alguns já estabelecidos, não foi sem uma certa dificuldade que conseguiu ver finalmente publicados em revistas internacionais da especialidade os artigos sobre este modelo, facto que, no entanto, não diminuiu o seu entusiasmo, continuando até à data a testar esse modelo. Pelo trabalho de investigação nesta área foi-lhe atribuído o Prémio Artur Malheiros da Academia das Ciências, em 1972.

Do seu currículo científico é também de salientar um conjunto de seis artigos sobre a Fotofísica do Ião Uranilo que contribuem com um novo modelo cinético para este sistema complexo.

Como fruto do seu trabalho em teorias de reactividade química e fotoquímica, o Professor Sebastião Formosinho dedica-se neste momento ao estudo de um modelo de transferência electrónica no estado excitado.

A sólida base de conhecimentos em Química e Física do Professor Formosinho, assim como o seu interesse em vários aspectos fundamentais e aplicados da Ciência e ainda a sua constante preocupação com a problemática do Ensino e Investigação e a sua função social, fazem de Sebastião Formosinho não só um Professor e Investigador muito respeitado e admirado pelos seus alunos, como ainda por todos os colegas e outras pessoas que têm beneficiado do seu convívio. 


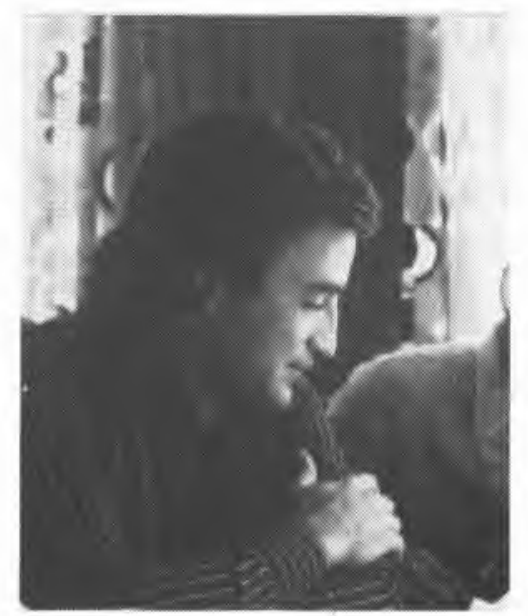

Descrever de um modo sucinto a actividade científica e pedagógica desenvolvida em Portugal pelo Prof. António V. Xavier é uma tarefa fácil se nos limitarmos a indicar de um modo objectivo o número de publicações e os interesses científicos - os números e os factos falam por si. Tal tarefa torna-se no entanto algo de muito complexo se se pretende transmitir, em poucas linhas, uma imagem correcta de uma personalidade multifacetada. Optou-se por apresentá-lo aqui de um modo objectivo. Assim, aqueles que o conhecem não necessitam de ler estas palavras. Àqueles que o não conhecem recomenda-se uma leitura rápida destas linhas e que o procurem conhecer pessoalmente. Se o fizerem, notarão que a sua dinâmica pessoal é contagiante.

O Prof. António Augusto de Vasconcelos Xavier nasceu no Porto, em 1943. É casado e tem dois filhos. Formou-se em Engenharia Química (Universidade do Porto - 1962-65 e Instituto Superior Técnico - 1965-69). Após estágio curricular efectuado no Instituto Gulbenkian de Ciência, parte para Inglaterra (1969-73) obtendo o grau de Doutor (D. Phil.) na Universidade de Oxford, Inorganic Chemistry Laboratory, sob a orientação do Prof. R.J.P. Williams (tese de doutoramento - Lanthanide Cations as Structural Probes). No ano de 1972-73 concorreu e foi nomeado para o lugar de Junior Research Fellow (Wolfson College, Universidade de Oxford). Regressa a Portugal em 1973, a convite do Prof. J.J.R. Fraústo da Silva e até 1975 ocupa a posição de Professor auxiliar do IST, tendo cumprido serviço militar durante parte desse período. Em 1975 ocupa a posição de Professor Extraordinário da Universidade Nova de Lisboa, sendo actualmente Prof. Catedrático da Faculdade de Ciências e Tecnologia da mesma Universidade e Responsável pela Secção Antónoma de Bioquímica. É Coordenador Científico do Grupo de Biofísica Molecular do Centro de Química Estrutural, Complexo I, INIC, desde 1973 e é membro da Direç̧ão deste Centro (actualmente Secretário do Centro). Esta última data marca de um modo decisivo o despontar do ramo de investigação que tem vindo a desenvolver em Portugal.

Entre as várias dinstinções de que a sua actividade científica tem vindo a ser alvo podemos destacar: convites de participação activa em encontros internacionais (por exemplo, Rare Earth Research Conferences Secção de Bioinorgânica, Gordon Conferences - Secção de Metais em Biologia, NMR Research International Symposia, FEBS, IUPAC, PAABS, etc.); Professor visitante da Universidade de Minnesota, EUA; Adjunct Full Professor of Biochemistry da Universi- dade de Minnesota e da Universidade da Georgia (EUA); condecoração "Ordre des Palmes Academiques"' do Governo Francês; membro das seguintes sociedades cientificas: British Biochemical Society, British Chemical Society, Sociedade Portuguesa de Química, Sociedade Portuguesa de Bioquímica e Sociedade Portuguesa de Biotecnologia; membro do Corpo Editorial do European Journal of Biochemistry e do Corpo Redactorial do Biochemical Journal, Inorganic Chimica Acta, da Revista Portuguesa de Química, da Ciência Biológica e da Bioquímica Aplicada; membro do FEBS Advanced Courses Committee; organizador de encontros científicos internacionais: NATO Advanced Study Institute on "Metal Ions in Biology", Tomar, Setembro de 1979, 2nd International Conference on Bioinoganic Chemistry e Special FEBS Meeting, Algarve, Abril de 1985.

Apresentou cerca de 80 conferências em instituições universitárias internacionais e publicou 100 artigos (25 durante o período de doutoramento) em revistas da especialidade com revisão prévia: Journal of Chemical Society (Dalton), European Journal of Biochemistry, Nature, Science, Biochimica Biophysica Acta, Biochemistry and Biophysic Research Communications, Journal of Chemical Society, Biochemistry, Journal of Biological Chemistry, Ann. N.Y. Academy of Sciences USA, Journal of Molecular Biology, FEBS Letters, etc. De salientar que um artigo seu, publicado em 1972 (Nature) foi considerado um dos artigos mais citados no ano seguinte à sua publicação.

Tem uma forte motivação pelo ensino, que tem leccionado nos seguintes domínios: Bioquímica Geral, Bioquímica Inorgânica, Espectroscopia, Ressonância Magnética Nuclear (aplicação a problemas biológicos). Tem participado activamente em diversos cursos de pós-graduação. Foi um dos iniciadores dos cursos de Mestrado em Portugal na Universidade Nova de Lisboa. Já orientou em Portugal seis teses de doutoramento.

$\mathrm{O}$ principal objectivo que tem vindo a orientar a actividade de investigador do Prof. António Xavier tem sido a compreensão da função biológica de iões metálicos e o desenvolvimento de técnicas espectroscópicas (em particular a ressonância magnética nuclear) na determinação da estrutura de moléculas em solução e a determinação da relação de dados estruturais com a função.

Grande parte da actividade desenvolvida em Oxford, durante o periodo de doutoramento, focou dois aspectos essenciais: o uso de iões lantanídeos como sondas estruturais, permitindo a obtenção de dados conformacionais de pequenas moléculas em solução, e o desenvolvimento de técnicas que permitissem um aumento espectacular de resolução espectral da ressonância magnética nuclear, tornando possível a aplicação desta técnica a moléculas complexas (por exemplo proteínas). Muitos dos métodos desenvolvidos são hoje de aplicação corrente (e.g., técnicas de deconvolução espectral).

Após a chegada a Portugal, os seus motivos de interesse orientam-se no sentido da aplicação de técnicas espectroscópicas ao estudo de proteínas de transferência electrónica (metaloenzimas) envolvidas em processos de interese bioenergético.

A sua motivação científica, interesse e exemplo, permitiram a consolidação de um grupo de investigação em Portugal (uma real criação de uma escola no domínio) com projecção na comunidade científica internacional. 